\title{
Physicochemical Comparison Between Recycled and Straight Run Polypropylene Yarn
}

\author{
Abdalaziz M. Seddeg ${ }^{1,3}$, Mohammed Margany ${ }^{2}$, Omsalama A. Alhafian $^{3}$, Hussain A. Hussain ${ }^{3}$, \\ Mohammed Noraldeen ${ }^{3}$, Mohamed N. Abdalaziz ${ }^{1, *}$ \\ ${ }^{1}$ Department of Chemistry, Faculty of Pure and Applied Science, International University of Africa, Khartoum, Sudan \\ ${ }^{2}$ Department of Industrial Chemistry, Faculty of Applied and Industrial Sciences, University of Bahri, Khartoum, Sudan \\ ${ }^{3}$ Khartoum Petrochemical Company (KPC), Khartoum, Sudan
}

Email address:

mohdnasr19@hotmail.com (M. N. Abdalaziz)

*Corresponding author

\section{To cite this article:}

Abdalaziz M. Seddeg, Mohammed Margany, Omsalama A. Alhafian, Hussain A. Hussain, Mohammed Noraldeen, Mohamed N. Abdalaziz. Physicochemical Comparison Between Recycled and Straight Run Polypropylene Yarn. American Journal of Polymer Science and Technology. Vol. 3, No. 4, 2017, pp. 70-75. doi: 10.11648/j.ajpst.20170304.13

Received: May 7, 2017; Accepted: May 31, 2017; Published: July 25, 2017

\begin{abstract}
In this research, investigating the possibility of producing, processing and also characterization of polypropylene fiber and recycling polypropylene has been presented. For this purpose, PP powder and inorganic filler were mixed using a twin screw extruder and modified granule was produced. After producing as-spun filament yarns by spinning machine at the take-up speed of $2000 \mathrm{~m} / \mathrm{min}$, samples were drawn, textured and finally weft knitted. Physical and structural properties of asspun and drawn yarns with constant and variable draw ratios were investigated. The experimental results revealed that the straight run PP yarn impact tolerance is higher than the recycled PP yarn. And both type of yarns could be compared by drawing process. The straight run and recycled polypropylene filament woven laminates performed better in terms of both tensile load and broken elongation, with slight decrease in broken elongation results.
\end{abstract}

Keywords: Polypropylene, Fiber, Extruder Machine

\section{Introduction}

Polypropylene (PP) is a linear hydrocarbon polymer, expressed as $\mathrm{C}_{\mathrm{n}} \mathrm{H}_{2 \mathrm{n}}$. PP, like polyethylene (High Density Poly Ethylene or Low Density Poly Ethylene) and polybutene $(\mathrm{PB})$, is a polyolefin or saturated polymer Polypropylene is one of those most versatile polymers available with applications' both as a plastic and as a fiber, in virtually all of the plastics end-use markets [1] [2].

Fiber reinforced composite materials are widely used in aerospace, automotive, military, wind energy, marine and civil engineering applications. However, their susceptibility to low and high velocity impacts still of major concern since induced damage can significantly reduce the residual strength of the composite laminates [3] [4].

Therefore, it is important to understand the effect of these types of impact damage on residual properties in order to develop damage tolerant composite laminates.

Several definitions are available in the literature to define the damage tolerance of composite laminates for example: Damage tolerance is the capability of a structure to withstand the creation of damage which resulting from external loads and the capability to maintain further loads [5].

Textile preforms are produced with different arrangement of reinforcement fibres which are impregnated with matrix resin part to form the fibre composite laminates. Fibre orientation, crimp and yarn interlacement affects the toughening and mechanical properties of final composite structures [6]. Textile preforms can be classified according to their fibre architecture such as woven, braided, knitted and non-crimp.

PP is used to manufacture a range of Sheet, Pipe, Compounding and Returnable Transport Packaging (RTP). With the exception of RTP where Injection Molding is used, extrusion dominates the conversion process used for these products. Some PP is utilized by the construction sector, most 
notable domestic drainage pipes [7].

Polypropylene is recyclable and has the number "5" as its resin identification code as below: $\widehat{\underbrace{5}_{\mathrm{p} p}}$.

Polypropylene is at room temperature resistant to fats and almost all organic solvents, apart from strong oxidants. Nonoxidizing acids and bases can be stored in containers made of PP. At elevated temperature, PP can be solved in of low polarity solvents (e.g. xylene, tetralin and decalin). Due to the tertiary carbon atom PP is chemically less resistant than PE. [8].

Most commercial polypropylene is isotactic and has an intermediate level of crystallinity between that of low-density polyethylene (LDPE) and high-density polyethylene (HDPE). Isotactic \&atactic polypropylene is soluble in P-xylene at $140^{\circ} \mathrm{C}$. The melt flow rate (MFR) or melt flow index (MFI) is a measure of molecular weight of polypropylene.

There are three general types of polypropylene: homo polymer, random copolymer, and block copolymer. The co monomer is typically used with ethylene. Ethylene-propylene rubber or EPDM added to polypropylene homo polymer increases its low temperature impact strength. Randomly polymerized ethylene monomer added to polypropylene homo polymer decreases the polymer crystallinity, lowers the melting point and makes the polymer more transparent.

The strength of the materials after the effects of environment, temperature, stress rate, damage stage can be predicted using damage tolerance investigation [9]. Structures need to be designed according to the two categories in order to fulfil damage tolerance concept for aerospace applications: (1) slow crack growth and (2) fail safe [10].

Poly Propylene is used for important parts (Barrel) of Syringes or granules practically insoluble in water, soluble in hot aromatic hydro carbons, practically insoluble in ethanol, in hexane and in methanol. It softness at temperature above about 120C [1].Therefore, the study was aimed to distinguish between PP filaments yarn and the recycle PP filament yarns in terms of mechanical prosperities and compare the quality of the both different types of PP filaments yarn according to Reference standards are ASTM D618 and ASTM D2256

\section{Materials and Methods}

\section{Instrument \& Equipment used in the laboratory}

Extrusion Plastometer Instrument, Extrudate Balance, Tensile \& Flexural Analyzer, Heat Deflection Temperature Instrument, Impact Resistance Tester Indicator, Temperature \& Relative Humidity Meter, Beakers, Pipettes, Cylinder, Rubber Pipits, Rubber Bags, Metal Bags, Cylinder Gas Sample, Sampling Containers, Cups.

Table 1. Materials and Chemicals.

\begin{tabular}{lll}
\hline NO. & Name & Exact Location \& unit \\
\hline 1 & HA-Calcium Stearate & Palletization unit \\
2 & 168-Tris(2,6-di-tert-butyl phenyl)phosphate & Palletization unit \\
3 & Nitrogen & All unit \\
4 & Hydrogen & Polymerization \\
5 & Acetone & Laboratory \\
6 & Propylene(get by separation it from liquefied petroleum gas) & Distillation \&Polymerization \\
7 & Polypropylene(get after polymerization reaction) & Polymerization \&Pelletization \\
8 & Recycled Polypropylene & Yarn process \\
9 & Zinc Oxide & Polymerization \\
10 & Di methoxydiphenylSilane & Polymerization \\
11 & Distill Water & Laboratory \\
12 & Titanium Tetrachloride & Laboratory \&Polymerization \\
\hline
\end{tabular}

\subsection{Methods of Sampling Powder}

Contact with the shift monitor to have the order. Wait for nitrogen and doesn't start sampling before ensure that the flow was stopped. Open the sampling valve few second to discharged the old sample, take the sample without delay. If you found negative nitrogen pressure closed the sampling valve quickly. Close the sampling valve tightly.

\subsection{Methods Operation for Apparatus}

\subsubsection{Melt Flow Rate (MFR)}

Weigh 6 grams sample into cup by balance, powder or granular. Added $5 \mathrm{ml}$ of stabilizer solution for powder sample, and then putted into heat oven for 10 minutes to be dried. Loaded test method, this method contains all necessary parameters. When the barrel temperature reach the test temperature, $230^{\circ} \mathrm{C}$, purge the barrel inside with nitrogen, putted sample into barrel little by little while pressing sample. Putted test piston stick and weight onto sample and start the test. Pressed test piston stick downward to eject out additional melted PP when elapsed time reaches 120 - 300 seconds. Started cutting after 420 seconds, weight the pieces and calculate the results. Cleaned the inside wall of barrel with cotton patches and purge it with nitrogen to clean.

\subsubsection{Heat Deflection Temperature (HDT)}

This test applied silicon oil as heat media and the temperature at deflection $0.25 \mathrm{~mm}$ is heat deflection temperature. Turned on the instrument connected with cooling water circulation, entered all the parameters, put the specimens into the oil bath, ensured the sensors were rezeroed, wait for initial temperature, applied weight and begin the test, automatically when the specimens deflected the instrument will register the deflection temperatures. Take the 
results, let the instrument cool below $50^{\circ} \mathrm{C}$ and turn it off. Disconnected the cooling circulation.

\subsubsection{Procedure of Notch Machine}

Cute depth is controlled by stationary screw. Ensured the safety cover is placed. put six specimens together below the clamped device, align them along sides, and then clamp them. Put down safety door, turned on the power, advanced the sample at constant speed by hand wheel until the stationary screw stop. Turned off power; lift up safety door, turned hand wheel anti clockwise, take out sample. Collected and take away the PP chip.

\subsection{Modulus Flexural Test}

Turned on instrument power and computer power in turn. Operated software, load the test method and enter all the parameters. Put specimen into vice, make specimen perpendicular to round support. Started the test specimen on the computer or pushed down test button on the instrument panel to start test. Take away sprain specimen after test finish, vice return back to initial position automatically.

\subsection{Tensile Test}

\subsubsection{Tensile Property}

Changed vice: loosen upper vice anti clock wisely and lower vice clock wisely with tool, pull out stationary pin, replace vice as required, fasten lower vice counter clock wise and upper vice clock wise, put extensometer into position as tensile test. Turned on instrument power and computer. Operated software and enter all the required parameters. Make mark onto specimen $25 \mathrm{~mm}$ and $57.5 \mathrm{~mm}$ from center line. Put specimen into vice, make $57.5 \mathrm{~mm}$ mark line close vice edge, make $25 \mathrm{~mm}$ mark line close extensometer round blade. Started the test on computer or push down test button on the instrument panel to start test. Take away broken specimen after test finish, vice return back to initial position automatically.

\subsubsection{Electronics Strength Tester Model YG026C Series}

The first step: turn on the switch of power supply of the instrument and make it run; double-click desktop shortcut mode, or click start key, chose all program, find the run icon of Model YG026C series electronics strength tester.

The second third step: Click the key of "Look over historical data" to look over historical data and may also choose printing and deleting historical test data,

The fourth step: click the key of "online" to communicate with the instrument and can get the information of test kind;

The fifth step: click the key of test kind and choose test kind;

The sixth step: click the key of "enter new test, enter into the interface of parameter set, input test factory, testing person, test name, drawing speed, etc.,

The eighth step: according to the keys of test interface, carry out concrete test: "zero" key will be used for cleaning out tare; "del" key will be used for deleting invalid test data; "display statistic value" key will be used for cleaning curve at interface, "minifying", "amplifying" key will be used for adjusting the best display status of curve, L, F may be used for changing its ratio value through two pull-down menu; "print curve" key will be used for printing the latest test curve, "return set page" key will be used for returning parameter set page, "inching up" and "inching down" key will be used for realizing inching up and inching down of instrument clamp; "confirm spacing distance" key will be used for confirming spacing distance and test run; "exit program" key will be used for exiting software.

The tenth step: Click "data saving" key to save data; click "printing" key, if choose 1, it will print the data and statistic result each time; if choose 2 , it will print statistic result data only; click "scan" key to scan the saved test data; click "exit" key to exit software.

\subsection{Statistical Analysis}

All data were presented as average. Statistical analysis for all the assays results were done using Microsoft Excel program (2010).

\section{Results and Discussion}

Table 2. Melt flow rate Test for semi-finished product.

\begin{tabular}{|c|c|c|c|}
\hline \multicolumn{4}{|c|}{ Test conditions } \\
\hline \multicolumn{2}{|c|}{ Cutting interval (t), s } & test Temperature, ${ }^{\circ} \mathrm{C}$ & Load, $\mathrm{Kg}$ \\
\hline \multicolumn{2}{|c|}{20} & 230 & 2.16 \\
\hline \multicolumn{4}{|l|}{ Test result } \\
\hline No. & \multicolumn{3}{|c|}{ Extrudate weight $(\mathrm{m}), \mathrm{g}$} \\
\hline 1. & 0.0999 & 0.0998 & 0.1000 \\
\hline 2. & 0.0984 & 0.0996 & 0.1000 \\
\hline 3. & 0.0996 & 0.0999 & 0.0992 \\
\hline $\begin{array}{l}\text { MFR Result, } \\
\mathrm{g} / 10 \mathrm{~min}\end{array}$ & 3.00 & 2.99 & 2.99 \\
\hline Average of MFR & \multicolumn{3}{|l|}{2.99} \\
\hline Quality status & \multicolumn{3}{|c|}{ The test is Pass according to limit test $(2-4) \mathrm{g} / 10 \mathrm{~min}$. } \\
\hline $\begin{array}{l}\text { Calculation } \\
\text { formula }\end{array}$ & \multicolumn{3}{|c|}{$\operatorname{MFR}(\mathrm{g} / 10 \mathrm{~min})=\mathrm{m} * 600 / \mathrm{t}$} \\
\hline
\end{tabular}

Where $\mathrm{m}=$ Mass., $\mathrm{t}=$ Time., $600=$ Factor.

Table 3. Melt flow rate Test for finished product.

\begin{tabular}{|c|c|c|c|}
\hline \multicolumn{4}{|l|}{ Test conditions } \\
\hline \multicolumn{2}{|c|}{ Cutting interval (t), $\mathrm{s}$} & test Temperature, ${ }^{\circ} \mathrm{C}$ & Load, $\mathrm{Kg}$ \\
\hline \multicolumn{2}{|l|}{20} & 230 & 2.16 \\
\hline \multicolumn{4}{|l|}{ Test result } \\
\hline No. & \multicolumn{3}{|c|}{ Extrudate weight $(\mathrm{m}), \mathrm{g}$} \\
\hline 1. & 0.0871 & 0.0872 & 0.0890 \\
\hline 2. & 0.0984 & 0.0996 & 0.1005 \\
\hline 3. & 0.0896 & 0.0899 & 0.0916 \\
\hline $\begin{array}{l}\text { MFR Result, } \\
\mathrm{g} / 10 \mathrm{~min}\end{array}$ & 2.83 & 2.99 & 2.71 \\
\hline $\begin{array}{l}\text { Average of } \\
\text { MFR }\end{array}$ & \multicolumn{3}{|l|}{2.78} \\
\hline Quality status & \multicolumn{3}{|c|}{ The test is Pass according to limit test $(2-4) \mathrm{g} / 10 \mathrm{~min}$. } \\
\hline $\begin{array}{l}\text { Calculation } \\
\text { formula }\end{array}$ & \multicolumn{3}{|c|}{$\operatorname{MFR}(\mathrm{g} / 10 \mathrm{~min})=\mathrm{m} * 600 / \mathrm{t}$} \\
\hline
\end{tabular}

Where $\mathrm{m}=$ Mass., $\mathrm{t}=$ Time., $600=$ Factor. 
Table 4. Heat Deflection Temperature Test for finished product.

\begin{tabular}{|c|c|c|c|c|}
\hline \multicolumn{5}{|c|}{ Preparation conditions of test specimens } \\
\hline Condition time, hour & Temperature, ${ }^{\circ} \mathrm{C}$ & \multicolumn{2}{|l|}{ Relative humidity, $\%$} & Injection method \\
\hline 48 & $23 \pm 2$ & \multicolumn{2}{|l|}{$50 \pm 5$} & ASTM D618 \\
\hline \multicolumn{5}{|l|}{ Size of test specimens } \\
\hline 3.2 & & \multicolumn{3}{|l|}{12.7} \\
\hline \multicolumn{5}{|l|}{ Test conditions } \\
\hline Immersion medium & Heating rate, ${ }^{\circ} \mathrm{C} / \mathrm{min}$ & \multicolumn{2}{|c|}{ Temperature at the start of the test, ${ }^{\circ} \mathrm{C}$} & Preheating, s \\
\hline \multicolumn{5}{|l|}{ Test result } \\
\hline No. & \multicolumn{2}{|l|}{ Corresponding fiber stress, $\mathrm{MPa}$} & \multicolumn{2}{|c|}{ Deflection temperature, ${ }^{\circ} \mathrm{C}$} \\
\hline 1. & \multicolumn{2}{|l|}{0.455} & \multicolumn{2}{|c|}{89.8} \\
\hline 2. & \multicolumn{2}{|l|}{0.455} & \multicolumn{2}{|l|}{95.2} \\
\hline \multicolumn{3}{|c|}{ Average Deflection temperature, ${ }^{\circ} \mathrm{C}$} & \multirow{2}{*}{\multicolumn{2}{|c|}{$92.5^{\circ} \mathrm{C}$}} \\
\hline Quality status & \multicolumn{2}{|c|}{ The test is Pass according to limit test $\left(>74^{\circ} \mathrm{C}\right)$. } & & \\
\hline
\end{tabular}

Table 5. Test of Flexural Property for finished product.

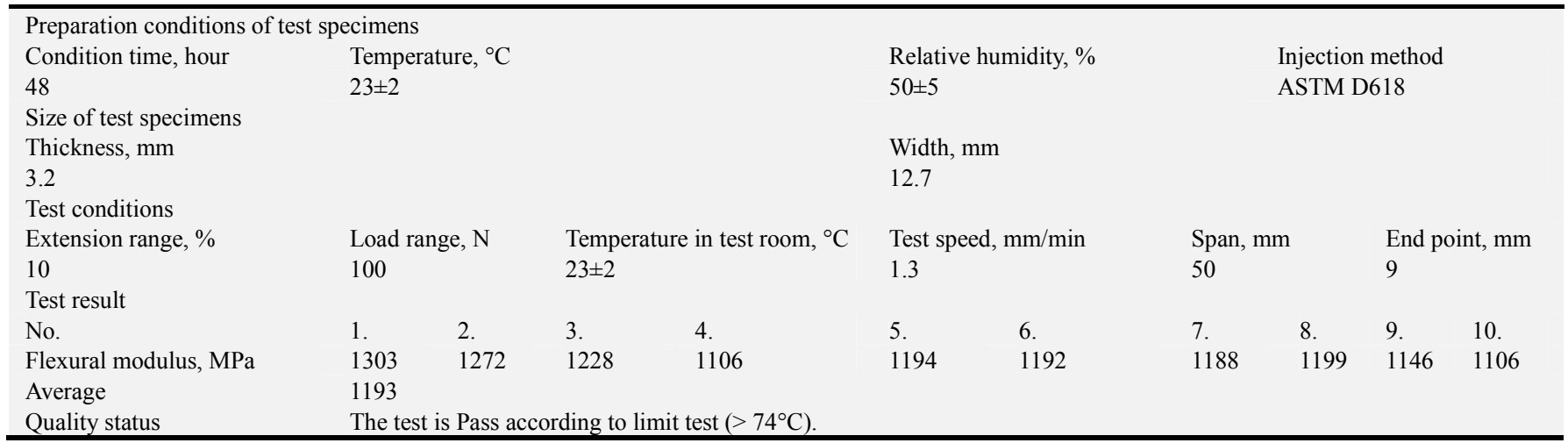

Table 6. Tensile Property test for finished product.

\begin{tabular}{|c|c|c|c|c|c|c|c|c|c|c|}
\hline \multicolumn{11}{|c|}{ Preparation conditions of test specimens } \\
\hline Condition time, hour & \multicolumn{5}{|c|}{ Temperature, ${ }^{\circ} \mathrm{C}$} & \multicolumn{3}{|c|}{ Relative humidity, \% } & \multicolumn{2}{|c|}{ Injection method } \\
\hline 48 & \multicolumn{5}{|c|}{$23 \pm 2$} & \multicolumn{3}{|c|}{$50 \pm 5$} & \multicolumn{2}{|c|}{ ASTM D618 } \\
\hline \multicolumn{11}{|l|}{ Size of test specimens } \\
\hline & \multicolumn{5}{|c|}{ Width, mm } \\
\hline 3.2 & & & & & & \multicolumn{5}{|c|}{12.7} \\
\hline \multicolumn{11}{|l|}{ Test conditions } \\
\hline Extension range, $\%$ & \multicolumn{2}{|c|}{ Load range, $N$} & \multicolumn{3}{|c|}{$\begin{array}{l}\text { Temperature in test room, }{ }^{\circ} \mathrm{C} \\
23 \pm 2\end{array}$} & \multicolumn{3}{|c|}{$\begin{array}{l}\text { Test speed, } \mathrm{mm} / \mathrm{min} \\
50\end{array}$} & \multicolumn{2}{|c|}{$\begin{array}{l}\text { Gauge length, } \mathrm{mm} \\
50\end{array}$} \\
\hline \multicolumn{11}{|l|}{ Test result } \\
\hline No. & 1. & 2. & 3. & 4. & 5. & 6. & 7. & 8. & 9. & 10. \\
\hline Tensile strength at yield, $\mathrm{MPa}$ & 35.03 & 34.36 & 34.58 & 34.92 & 34.25 & 33.29 & 34.14 & 34.58 & 32.59 & 33.81 \\
\hline Average & 34.15 & & & & & & & & & \\
\hline Quality status & \multicolumn{10}{|c|}{ The test is Pass according to limit test ( $>27 \mathrm{MPa})$. } \\
\hline
\end{tabular}

Table 7. Test Record for Yarn(White).

\begin{tabular}{|c|c|c|c|c|c|c|c|c|}
\hline \multirow{2}{*}{ No } & \multirow{2}{*}{ Test item } & \multicolumn{6}{|c|}{ Test Result } & \multirow{2}{*}{ Standard Specification } \\
\hline & & Sample1 & Sample 2 & Sample 3 & Sample 4 & Sample 5 & Sample 6 & \\
\hline 1 & Appearance & Good & Good & Good & Good & Good & Good & $\begin{array}{l}\text { Clean without oil spot } \\
\text { and no twist }\end{array}$ \\
\hline 2 & Width, mm & 2. 49 & 2.45 & 2.52 & 2.50 & 2.52 & 2.46 & $\begin{array}{l}\text { 口 } 1.92 \sim 2.02 \\
\text { 口 } 2.42 \sim 2.52\end{array}$ \\
\hline 3 & Thickness, mm & 0.050 & 0.047 & 0.050 & 0.050 & 0.05 & 0.050 & $\begin{array}{l}\text { 口 } 0.05 \sim 0.055 \\
\text { 口 } 0.045 \sim 0.05\end{array}$ \\
\hline 4 & Linear density, Daniel & 916 & 929 & 954 & 895 & 890 & 900 & $\begin{array}{l}\text { 口 } 800 \sim 880 \\
\text { 口 } 900 \sim 990\end{array}$ \\
\hline 5 & Broken strength, $\mathrm{N}$ & 51.3 & 45.1 & 50.3 & 46.3 & 44.1 & 44.3 & $\geq 35$ \\
\hline 6 & Broken elongation, $\%$ & 16.5 & 16.2 & 17.3 & 13.5 & 11.1 & 9.9 & $15 \sim 30$ \\
\hline 7 & Broken intensity, N/tex & 0.54 & 0.50 & 0.53 & 0.43 & 0.42 & 0.41 & $\geq 0.32$ \\
\hline \multicolumn{2}{|c|}{ Quality status } & Pass & Pass & Pass & Failed & Failed & Failed & \\
\hline \multicolumn{2}{|c|}{ Remark } & -- & -- & -- & $4 / 6$ & $4 / 6$ & 6 & \\
\hline
\end{tabular}


Table 8. Test Record for Yarn(Blue).

\begin{tabular}{|c|c|c|c|c|c|c|c|c|}
\hline \multirow{2}{*}{ No } & \multirow{2}{*}{ Test item } & \multicolumn{6}{|c|}{ Test Result } & \multirow{2}{*}{ Standard Specification } \\
\hline & & Sample1 & Sample 2 & Sample 3 & Sample 4 & Sample 5 & Sample 6 & \\
\hline 1 & Appearance & Good & Good & Good & Good & Good & Good & $\begin{array}{l}\text { Clean without oil spot } \\
\text { and no twist }\end{array}$ \\
\hline 2 & Width, mm & 2.52 & 2.45 & 2.49 & 2.50 & 2.52 & 2.46 & $\begin{array}{l}\text { ㅁ } 1.92 \sim 2.02 \\
\text { ㅁ } 2.42 \sim 2.52\end{array}$ \\
\hline 3 & Thickness, mm & 0.050 & 0.049 & 0.050 & 0.048 & 0.050 & 0.050 & $\begin{array}{l}\text { ㅁ } 0.05 \sim 0.055 \\
\text { } 0.045 \sim 0.05\end{array}$ \\
\hline 4 & Linear density, Daniel & 863 & 856 & 855 & 797 & 825 & 800 & $\begin{array}{l}\text { 口 } 800 \sim 880 \\
\text { ロ } 900 \sim 990\end{array}$ \\
\hline 5 & Broken strength, $\mathrm{N}$ & 43.7 & 44.3 & 43.9 & 34.9 & 33.6 & 35.9 & $\geq 35$ \\
\hline 6 & Broken elongation, $\%$ & 15.7 & 15.8 & 14.4 & 12.7 & 12.7 & 13.7 & $15 \sim 30$ \\
\hline 7 & Broken intensity, $N /$ tex & 0.43 & 0.44 & 0.45 & 0.40 & 0.40 & 0.40 & $\geq 0.32$ \\
\hline \multicolumn{2}{|c|}{ Quality status } & Pass & Pass & Failed & Failed & Failed & Failed & \\
\hline \multicolumn{2}{|c|}{ Remark } & -- & -- & 6 & $4 / 5 / 6$ & $5 / 6$ & 6 & \\
\hline
\end{tabular}

Table 9. Test Record for tensile load of final Woven Sacks Products.

\begin{tabular}{|c|c|c|c|c|c|c|c|}
\hline \multicolumn{2}{|l|}{ Instrument } & \multicolumn{2}{|l|}{ Model } & Sacks Type & \multirow{2}{*}{$\begin{array}{l}\text { Sacks Model } \\
560 * 940 \text { (White) }\end{array}$} & \multirow{2}{*}{$\begin{array}{l}\text { Sample date } \\
\text { February 21, } 2017\end{array}$} & Test date \\
\hline Electric fat & h tester & YG026C & & Common woven sack & & & February 21, 2017 \\
\hline \multicolumn{8}{|c|}{ Test Result of Tensile Load, N/50mm } \\
\hline No. & Warp di & ection & & & Average & Quality status & Standard specification, $\%$ \\
\hline Sample 1. & 827.1 & & 810.0 & 967.7 & 868.3 & Pass & \\
\hline Sample 2. & 865.0 & & 852.3 & 801.9 & 839.7 & Pass & \\
\hline Sample 3. & 506.4 & & 495.6 & 510.0 & 504.0 & Pass & \\
\hline No. & Woof d & ection & & & Average & -- & $\geq 500$ \\
\hline Sample 1. & 704.6 & & 760.4 & 636.1 & 700.4 & Pass & \\
\hline Sample 2. & 902.8 & & 894.7 & 801.0 & 866.2 & Pass & \\
\hline Sample 3. & 493.8 & & 556.9 & 546.9 & 532.5 & Pass & \\
\hline
\end{tabular}

Table 10. Test Record for Brocken elongation of final Woven Sacks Products.

\begin{tabular}{|c|c|c|c|c|c|c|c|}
\hline \multicolumn{2}{|c|}{ Instrument } & \multicolumn{2}{|l|}{ Model } & Sacks Type & \multirow{2}{*}{\begin{tabular}{|l} 
Sacks Model \\
$560 * 940$ (White)
\end{tabular}} & \multirow{2}{*}{$\begin{array}{l}\text { Sample date } \\
\text { February 21, } 2017\end{array}$} & \multirow{2}{*}{$\begin{array}{l}\text { Test date } \\
\text { February 21, } 2017\end{array}$} \\
\hline Electric fa & h tester & YG026C & & Common woven sack & & & \\
\hline \multicolumn{8}{|c|}{ Test Result of Brocken elongation, \% } \\
\hline No. & Warp di & ction & & & Average & Quality status & Standard specification, $\%$ \\
\hline Sample 1. & 16.3 & & 15.5 & 16.2 & 16.0 & Pass & \\
\hline Sample 2. & 15.2 & & 15.9 & 15.7 & 15.6 & Pass & \\
\hline Sample 3. & 14.9 & & 13.2 & 14.9 & 14.3 & Fail & \\
\hline No. & Woof d & ction & & & Average & -- & $15 \sim 30$ \\
\hline Sample 1. & 15.3 & & 16.4 & 15.3 & 15.7 & Pass & \\
\hline Sample 2. & 16.1 & & 16.2 & 15.3 & 15.9 & Pass & \\
\hline Sample 3. & 14.4 & & 13.7 & 14.6 & 14.2 & Fail & \\
\hline
\end{tabular}

Discussion of results:

a) The result of Melt Flow Rate (MFR): (2.78 and 2.99) $\mathrm{g} / 10 \mathrm{~min}$ both results are on specification range (2 to 4 ).

b) The result of Impact resistance: $38.6 \mathrm{~J} / \mathrm{m}$ this result is on specificationrange $(>25 \mathrm{~J} / \mathrm{m})$.

c) The result of Heat deflection temperature (HDT): $92.5^{\circ} \mathrm{C}$ this result is on specification range $\left(>74^{\circ} \mathrm{C}\right)$.

d) The result of Tensile property: $34.15 \mathrm{Mpa}$ this result is on specification range $(>27.50 \mathrm{Mpa})$.

e) The result of Flexural property: $1193.4 \mathrm{Mpa}$ this result is on specification range ( $>1000 \mathrm{Mpa})$.

f) The result of broken elongation in the straight run/ recycled pp white yarn: $16.6 \%$ and $11.5 \%$ respectively.

g) The result of broken elongation in the straight run/ recycled pp blue yarn: $15.3 \%$ and 13.0 respectively. h) The result of tensile load of final Woven Sacks Products, straight run/ recycled:854.0, 504.3 N/50mm respectively, warp direction. And783.3, 532.5 $\mathrm{N} / 50 \mathrm{mmwoof}$ direction.

i) The result of Broken Elongation of final Woven Sacks Products, straight run/ recycled: 15.8, 14.3\% respectively, warp direction. And 15.8, 14.2\% respectively woof direction.

j) During this study and from the results on different samples, I have found that: Recycled polypropylene yarn samples (4, 5 and 6) has very small result of broken elongation comparing with Straight run polypropylene yarn samples (1,2 and 3).

These above results of tests are according to ASTM _Methods, American Society Testing \&Materials 
Table 11. Table of results.

\begin{tabular}{lllll}
\hline No. & Test Items & Results & Unit & Specification of Low density \\
\hline 1 & Melt flow rate (MFR)semi-finished & 2.99 & $\mathrm{~g} / 10 \mathrm{~min}$ & $1.00-4.00$ \\
2 & Melt flow rate (MFR) finished & 2.78 & $\mathrm{~g} / 10 \mathrm{~min}$ & $2.00-4.00$ \\
3 & Impact resistance finished & 38.6 & $\mathrm{~J} / \mathrm{m}$ & $>25.00$ \\
4 & Heat deflection temperature (HDT) finished & 92.5 & ${ }^{\circ} \mathrm{C}$ & $>74.00$ \\
5 & Tensile property Finished & 34.15 & $\mathrm{MPa}$ & $>27.50$ \\
6 & Flexural property Finished & 1193.4 & $\mathrm{MPa}$ & $>1000$ \\
7 & Density test Finished & 892.1 & $\mathrm{Kg} / \mathrm{m}^{3}$ & $<910$ \\
8 & Broken elongation of straight run yarn (white) & 16.6 & $\%$ & $15 \sim 30$ \\
9 & Broken elongation of recycled yarn (white) & 11.5 & $\%$ & $15 \sim 30$ \\
10 & Brocken elongation of straight run yarn (blue) & 15.3 & $\%$ & $15 \sim 30$ \\
11 & Brocken elongation of recycled yarn (blue) & 13.0 & $\%$ & $\geq 500$ \\
12 & Tensile load of straight run final Woven Sacks & 818.7 & $\mathrm{~N} / 50 \mathrm{~mm}$ & $\geq 500$ \\
13 & Tensile load of recycled final Woven Sacks & 518.4 & $\mathrm{~N} / 50 \mathrm{~mm}$ & $15 \sim 30$ \\
14 & Broken Elongation of straight run final Woven Sacks & 15.8 & $\%$ & $15 \sim 30$ \\
15 & Broken Elongation of recycled final Woven Sacks & 14.2 & $\%$ & $\%$ \\
\hline
\end{tabular}

\section{Conclusion}

Hybrid composites yarn in different preform structures were produced the experimental test results show that, the straight run PP yarn impact tolerance is higher than the recycled PP yarn.

Based on data presented in this study, the straight run and recycled polypropylene filament woven laminates performed better in terms of both tensile load and broken elongation, with slight decrease in broken elongation result.

\section{Acknowledgements}

We are grateful to Khartoum Petrochemical Company (KPC) staff, Khartoum, Sudan and Mr. Altahir Mohammed for his technical supports for the equipment and necessary materials for my research and special thanks to Dr. Mahmoud Mohamed Ali, Head Department of Chemistry, Faculty of Pure and Applied Science, International University of Africa.

\section{References}

[1] Kostar, T. D. and Chou, T.-W., A methodology for Cartesian braiding of three-dimensional shapes and special structures. Journal of Materials Science, 2002. 37 (13): p. 2811-2824.
[2] Tolosana, N., Lomov, S., Stuve, J., and Miravete, A. Development of a Simulation Tool for 3D Braiding Architectures. AIP Conference Proceedings, 2007. 907 (1): p. 1005-1010.

[3] Shi, Y., Swait, T., and Soutis, C., Modelling damage evolution in composite laminates subjected to low velocity impact. Compos. Struct., 2012.94 (9): p. 2902-2913.

[4] Christoforou, A., Yigit, A., Cantwell, W., and Yang, F., Impact Response Characterization in Composite PlatesExperimental Validation. Applied Composite Materials, 2010. 17 (5): p. 463-472.

[5] Hull, D. and Shi, Y. B., Damage Mechanism Characterization in Composite Damage Tolerance Investigations. Composite Structures, 1993. 23 (2): p. 99-120.

[6] Miravete, A., 3-D textile reinforcements in composite materials. 1999: CRC Press.

[7] Generation III Extended Cold Weather Clothing System (ECWCS). PM Soldier Equipment. October 2016.

[8] Benedikt, G. M. and Goodall, B. L. (eds.) (1998) Metallocene Catalyzed Polymers, ChemTech Publishing: Toronto. ISBN 978-1-884207-59-4.

[9] Sierakowski, R. and Newaz, G., Damage Tolerance in Advanced Composites. 1995: Technomic Pub. Co.

[10] Biaxially Oriented Polypropylene Films. Granwell. Retrieved: 2012-05-31. 